\title{
SELEÇÃO DE CARVÃO ATIVADO PULVERIZADO PARA PÓS- TRATAMENTO DE LIXIVIADO DE ATERROS SANITÁRIO
}

\author{
Jandiara Damaris Campos Pozzetti
}

Vilson Gomes da Assunção Junior

Aline Domingues Batista

Emília Kiyomi Kuroda

RESUMO: Várias pesquisas vêm sendo realizadas para tratar lixiviados de aterro sanitário por processos biológicos, físicos e químicos antes de seu lançamento no corpo receptor. No entanto, vários estudos realizados no Brasil com lixiviado estabilizado de aterro sanitário têm indicado que o tratamento por coagulação química, floculação e sedimentação/flotação não é suficiente para produzir efluentes com qualidade adequada aos padrões estabelecidos pelas legislações vigentes, fazendo-se necessário o uso de processos complementares de tratamento como polimento, tais como a adsorção em carvão ativado pulverizado. Nesse sentido este trabalho foi realizado com o objetivo de selecionar os carvões ativados pulverizados de melhor desempenho a serem aplicados no pós-tratamento por coagulação química, floculação e sedimentação de lixiviado estabilizado de aterro sanitário, tratado previamente por stripping de amônia, seguido de tratamento biológico por lodos ativados em bateladas sequenciais, considerando a remoção de matéria orgânica correlacionada à cor verdadeira. Os CAPs amostrados foram caracterizados em relação ao Número de lodo - NI, Índice de Fenol - IF e Índice de Azul de Metileno - IAM e submetidos ao ensaio de adsorção aliada à coagulação química, floculação e sedimentação. Dos valores de cor verdadeira residual correlacionados aos índices de adsorção da caracterização dos CAPs, pôde-se verificar relação direta entre a eficiência observada e o IAM dos CAPs amostrados, com $R^{2}$ de 0,93 , sendo os CAPs 
mais eficientes aqueles de maior IAM, reafirmando a hipótese de que os mesoporos constituem os sítios de adsorção de moléculas orgânicas de elevada massa molecular que conferem cor ao lixiviado como as substâncias húmicas.

\section{INTRODUÇÃO}

A disposição de resíduos sólidos urbanos - RSU a céu aberto foi a única forma de disposição de resíduos até o século XIX, mas graças ao aumento da preocupação ambiental e sanitária, surgiram no início do século $X X$, os primeiros aterros sanitários na Europa (SANTOS, 2008). Atualmente, mesmo com as técnicas de reutilização, segregação e reciclagem, o volume remanescente de resíduos para disposição final ainda é elevado, principalmente no Brasil.

Os aterros sanitários são obras de engenharia para confinar os resíduos de forma ambiental e sanitariamente segura. Eles devem ser impermeabilizados ou selados em sua base, para evitar a contaminação dos lençóis freáticos e contar com sistemas de drenagem e escoamento das águas superficiais, sistemas de drenagem e tratamento da água infiltrada e dos gases gerados. Quando chove, a água que percola o aterro passa através das camadas de resíduos e extrai / lixivia uma série de contaminantes. Esse percolado ou lixiviado torna-se então um problema, já que contêm grandes quantidades de matéria orgânica, nitrogênio amoniacal, metais pesados, sais inorgânicos e organoclorados que são substâncias tóxicas aos organismos vivos e aos ecossistemas (WEl et al., 2010).

Visando à preservação da vida aquática e a manutenção da qualidade dos corpos hídricos, valores-limite de poluentes para o descarte de efluentes em corpos hídricos foram estabelecidos pelas legislações CONAMA 357/2005, CONAMA 430/2011, CEMA №. 0070/2009 e CEMA №. 081/2010, incluindo valores máximos de DQO, nitrogênio amoniacal, metais e toxicidade, o que requer o tratamento do lixiviado de aterro sanitário antes de seu lançamento no corpo receptor. 
Várias pesquisas vêm sendo realizadas para tratar lixiviados de aterro sanitário por processos biológicos, físicos e químicos (SLETTEN et al., 1995; AMOKRANE et al., 1997; KURNIAWAN et al., 2006). Kurniawan et al.(2006) revisaram 118 artigos publicados entre 1983 e 2005 e verificaram que processos físico-químicos utilizados como etapa de refinamento ao tratamento biológico são eficientes para a remoção de substâncias refratárias. No entanto, vários estudos realizados no Brasil com lixiviado estabilizado de aterro sanitário têm indicado que o tratamento por coagulação química, floculação e sedimentação/flotação não é suficiente para obter efluentes com qualidade adequada aos padrões estabelecidos pelas legislações vigentes, fazendo-se necessário o uso de processos complementares de tratamento como polimento (FELICI, 2010; CASTRO, 2012; KAWAHIGASHI, 2012; MALER, 2013).

Processos de pós-tratamento para lixiviados podem incluir além da coagulação química, floculação e sedimentação/flotação, a precipitação química, processos adsortivos, oxidativos, filtração por membranas, entre outros (SANTOS, 2008). Dentre esses processos, a adsorção em carvão ativado tem se mostrada promissora uma vez que o carvão ativado apresenta grande capacidade de adsorção de matéria orgânica (KAWAHIGASHI, 2012) e metais (MODIN et al., 2011).

Devido à diversidade de compostos orgânicos existentes nas águas residuárias, a escolha do carvão ativado para a remoção de matéria orgânica tem sido arbitrária (BANSAL, 1998). Entretanto, o estudo das propriedades físicas e químicas da superfície do carvão pode orientar a seleção do melhor adsorvente para otimizar o processo visando a remoção desses compostos.

A capacidade adsortiva de um material depende de fatores intrínsecos do adsorvente, tais como a estrutura interna, forma, volume e distribuição dos poros, química da superfície, modo de ativação do material, teor de cinzas, assim como das condições experimentais de reação, tais como $\mathrm{pH}$, temperatura, grau de agitação, tempo de contato entre adsorvato e adsorvente, particularidades do efluente, entre outros fatores que podem dificultar ou favorecer o processo de adsorção (KURODA et al., 2005). 
Dentre as principais características dos carvões ativados podem-se destacar a área superficial, a distribuição do tamanho e volume dos poros e a habilidade de adsorção de substâncias como iodo, fenol e metileno em meio aquoso.

Os carvões ativados podem alcançar áreas superficiais que variam de 400 a 1500 $\mathrm{m}^{2} \mathrm{~g}^{-1}$ (BANSAL et al., 1988). O tamanho do diâmetro dos poros é classificado em micro, meso e macroporos, conforme a IUPAC:

Macroporos: maiores do que $50 \mathrm{~nm}$;

Mesoporos: entre 2 e $50 \mathrm{~nm}$;

Microporos: menores do que $2 \mathrm{~nm}$.

As propriedades de adsorção são geralmente estimadas através da determinação de isotermas de adsorção. Isso é feito submetendo o carvão ativado à adsorção de uma substância em uma solução padrão até alcançar o parâmetro de referência (concentração de equilíbrio, tempo de contato determinado, ou outro padrão de referência). Como a distribuição porosa dos carvões é muito ampla, recomenda-se a construção de isotermas em relação a compostos específicos para estimativa da distribuição porosa do carvão ou da aplicabilidade deste em uma determinada matriz (JANKOWSKA et al., 1991; CEFIC, 1986). Os índices mais utilizados são apresentados a seguir.

Número de lodo - NI: É definido pela NBR 12073/1991 como a quantidade de iodo adsorvido em mg por g de carvão quando a concentração de iodo total no equilíbrio é de $2,5 \mathrm{~g} \mathrm{~L}^{-1}$. O número de iodo é um indicativo da área superficial interna dos carvões ativados (CEFIC, 1986).

Índice de Fenol - IF: É definido pela NBR 12074/1991 como a quantidade (em gramas) de carvão ativado pulverizado necessária para reduzir a concentração de $1 \mathrm{~L}$ da solução-padrão de fenol de 200 a $20 \mathrm{mg} \mathrm{L}^{-1}$. O índice de fenol é um indicativo das propriedades sortivas do carvão ativado no tratamento de águas (CEFIC, 1986).

Índice de Azul de Metileno - IAM: Segundo a norma japonesa JIS K 1474/1991 é definido como a quantidade de azul de metileno adsorvido em mg por g de carvão quando a concentração residual é de $0,24 \mathrm{mg} \mathrm{L}^{-1}$.É um indicativo do volume de poros de dimensões maiores que a molécula de azul de metileno - 1,5 nm (BANSAL et al., 1988). Essas moléculas são preferencialmente adsorvidas por poros com abertura máxima 
próxima a 2,0 nm (WARHURST et al., 1997) estando portando mais relacionada à mesoporosidade do carvão ativado, conforme confirmado por Baçaoui et al. (2001) e Kuroda (2006).

\section{OBJETIVO}

Selecionar os carvões ativados pulverizados de melhor desempenho a serem aplicados no pós-tratamento por coagulação química, floculação e sedimentação de lixiviado estabilizado de aterro sanitário, tratado previamente por stripping de amônia, seguido de tratamento biológico por lodos ativados em bateladas sequenciais, considerando a remoção de matéria orgânica correlacionada à cor verdadeira.

\section{DESENVOLVIMENTO}

\section{MATERIAL E MÉTODOS}

O lixiviado bruto foi coletado no aterro controlado de resíduos sólidos domiciliares da cidade de Londrina - PR, localizado às margens da estrada "Água do Limoeiro", no lote 23-C da Gleba Cambé em funcionamento no período de 1974-2010 com características de lixiviado estabilizado. Após coleta, o lixiviado foi armazenado em um reservatório de fibra de vidro com capacidade volumétrica de 15 m3 no Laboratório de Hidráulica e Saneamento da UEL.

O lixiviado coletado foi submetido ao tratamento preliminar por stripping de amônia e tratamento biológico por lodos ativados, em instalação piloto de $1 \mathrm{~m}^{3}$ de capacidade, e bateladas sequenciais para remoção da série nitrogenada, segundo metodologias utilizadas por Hossaka (2008), Alvim (2010) e Felici (2010), resultando assim no lixiviado de estudo.

\section{Amostragem e caracterização de carvões ativados pulverizados - CAPs}


Foram adquiridas quatorze amostras de CAPs disponíveis no mercado nacional e internacional com condições diversificadas de origem, matéria prima, método de ativação e propriedades físicas e químicas, cujas características são relacionados na Tabela 1.

Tabela 1- Características dos carvões ativados pulverizados amostrados.

\begin{tabular}{cccc}
\hline Índice & Origem & Ativação & Matéria-prima \\
\hline 1 & Vegetal & Física & Babaçu \\
2 & Vegetal & Física & Babaçu \\
3 & Vegetal & Física & Pinus \\
4 & Vegetal & Física & Pinus \\
5 & Vegetal & Física & Pinus \\
$6^{(*)}$ & Mineral & Química & Mineral betuminoso \\
$7^{(*)}$ & Animal & Química & Osso \\
$8^{(*)}$ & Animal & Química & Osso \\
9 & Vegetal & Física & Madeira \\
10 & Vegetal & Física & Madeira \\
11 & Vegetal & Física & Madeira \\
12 & Animal & Física & Osso \\
13 & Vegetal & Física & Madeira \\
14 & Vegetal & Física & Côco \\
\hline \multicolumn{5}{c}{${ }^{(*)}$ CAPs importados }
\end{tabular}

A maioria dos carvões amostrados é de origem vegetal e ativação física, uma vez que estas são as mais comumente encontradas no mercado nacional. Não foram encontrados carvões com ativação química de produção nacional. Neste estudo, os CAPs serão tratados pelos índices (1 a 14).

Os CAPs amostrados foram caracterizados em relação ao Número de lodo - $\mathrm{NI}$ e Índice de Fenol - IF, parâmetros estabelecidos pela norma brasileira NBR 11834/1991 EB - 2133 e Índice de Azul de Metileno - IAM estabelecido pela Japanese Industrial Standard - JIS K 147. Essas análises foram realizadas no Laboratório da Empresa AlphaCarbo em Guarapuava-PR.

\section{Experimento de adsorção aliada à coagulação química, floculação e sedimentação}

Considerando a condição de aplicação da adsorção em CAP aliada à coagulação química, floculação e sedimentação como pós-tratamento foram utilizados os parâmetros de controle operacionais determinados por Pozzetti et al. (2013): tempo médio de mistura rápida $T_{m r}=1 \mathrm{~min}$; gradiente de velocidade médio de mistura rápida $G_{m r}=600 \mathrm{~s}^{-1}$; tempo 
médio de floculação $T_{\text {floc }}=20$ min; gradiente de velocidade médio de floculação $G_{\text {floc }}=20$ $\mathrm{s}^{-1}$ e velocidade de sedimentação $V_{S}=0,117 \mathrm{~cm} \mathrm{~min}^{-1}$, o que corresponde a $1,0 \mathrm{~h}$ de tempo de sedimentação.

Os ensaios foram realizados em escala de bancada com a utilização do equipamento Jarteste (Nova Ética - 218/6LDBE) - Figura 1. Este é composto de 6 jarros de acrílico transparente de $2 \mathrm{~L}$, tacômetro digital para visualização da rotação (até 600 rpm $\pm 2 \%$ ), o que confere gradiente de velocidade de até $1.200 \mathrm{~s}^{-1}$, dispositivo para aplicação de produtos químicos nos 6 jarros simultaneamente.

Figura 1 - Foto do equipamento Jarteste com o lixiviado de estudo.

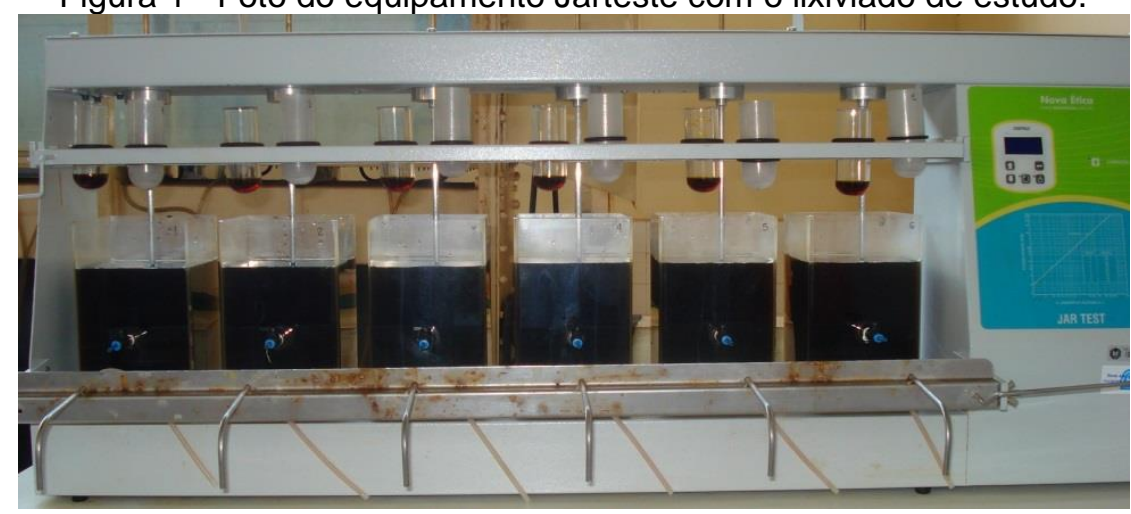

Fonte: Kawahigashi (2013)

Para realização dos ensaios foram utilizados os produtos químicos:

- Solução comercial de ácido clorídrico com 37\% em massa e massa específica $=1,187 \mathrm{~kg} \mathrm{~L}^{-1}$ como acidificante, para preparação de solução com concentração de $150 \mathrm{~g} \mathrm{~L}^{-1}$;

- Solução comercial de cloreto férrico líquido com $39,4 \%$ de $\mathrm{FeCl}_{3} \cdot 6 \mathrm{H}_{2} \mathrm{O}$, massa específica $=1,42 \mathrm{~kg} \mathrm{~L}^{-1}$ e cor amarela como coagulante, para preparação de solução com concentração de $80 \mathrm{~g} \mathrm{~L}^{-1}$ de $\mathrm{Fe}^{3+}$.

Devido à elevada eficiência do tratamento por coagulação química, floculação e sedimentação em relação à remoção de cor verdadeira, no ensaio de seleção dos melhores CAPs optou-se pela aplicação da dosagem de $\mathrm{Fe}^{3+}$ de $100 \mathrm{mg} \mathrm{L}^{-1}$, dosagem de coagulante reduzida a $25 \%$ da dosagem ótima obtida por Pozzetti (2013) (dosagem de 
$\mathrm{Fe}^{3+}$ de $400 \mathrm{mg} \mathrm{L}^{-1}$ ), mantendo-se o pH em 4,0 com associação da dosagem de $1000 \mathrm{mg}$ $\mathrm{L}^{-1}$ para cada um dos CAPs amostrados mantendo-se os demais parâmetros operacionais.

A análise de cor verdadeira residual do sobrenadante, após $1 \mathrm{~h}$ de sedimentação, foi realizada após filtração em membrana de éster de celulose com porosidade média de 0,45 $\mu \mathrm{m}$, segundo método espectrofotométrico $2120 \mathrm{C}$ do APHA, AWWA, WEF (2005) em Espectrofotômetro Cary 60 UV-Vis da Agilent.

\section{RESULTADOS E DISCUSSÃO}

\section{Caracterização dos carvões ativados pulverizados}

Os resultados da caracterização dos CAPs amostrados em relação ao Número de lodo, Índice de Fenol e Índice de Azul de Metileno são apresentados na Tabela 2.

Tabela 2 - Resultado da caracterização dos CAPs amostrados em relação ao NI, IF e IAM.

\begin{tabular}{ccccccc}
\hline Índice & Origem & Ativação & Matéria-prima & $\begin{array}{c}\mathbf{N I} \\
\left(\mathbf{m g ~ g}^{-1}\right)\end{array}$ & $\begin{array}{c}\text { IAM } \\
\left(\mathbf{m g ~ g}^{-1}\right)\end{array}$ & $\begin{array}{c}\mathbf{I F} \\
\left(\mathbf{g ~ L}^{-1}\right)\end{array}$ \\
\hline $\mathbf{1}$ & Vegetal & Física & Babaçu & 853 & 75 & 2,06 \\
$\mathbf{2}$ & Vegetal & Física & Babaçu & 934 & 88 & - \\
$\mathbf{3}$ & Vegetal & Física & Pinus & 629 & 42 & 2,26 \\
$\mathbf{4}$ & Vegetal & Física & Pinus & 862 & 108 & - \\
$\mathbf{5}$ & Vegetal & Física & Pinus & 942 & 134 & 2,07 \\
$\mathbf{6}^{(*)}$ & Mineral & Química & $\begin{array}{c}\text { Mineral } \\
\text { betuminoso }\end{array}$ & 966 & 142 & - \\
$\mathbf{7}^{(*)}$ & Animal & Química & Osso & 1130 & 203 & 2,10 \\
$\mathbf{8}^{(*)}$ & Animal & Química & Osso & 1098 & 199 & 2,15 \\
$\mathbf{9}$ & Vegetal & Física & Madeira & 1019 & 171 & - \\
$\mathbf{1 0}$ & Vegetal & Física & Madeira & 765 & 116 & - \\
$\mathbf{1 1}$ & Vegetal & Física & Madeira & 621 & 98 & - \\
$\mathbf{1 2}$ & Animal & Física & Osso & 4 & 16 & - \\
$\mathbf{1 3}$ & Vegetal & Física & Madeira & 465 & 67 & - \\
$\mathbf{1 4}$ & Vegetal & Física & Côco & 770 & 133 & 3,07 \\
\hline
\end{tabular}

No Brasil, segundo a NBR 11834/1991 o limite mínimo do número de iodo - NI para carvões a serem utilizados em Estações de Tratamento de Águas é de $600 \mathrm{mg} \mathrm{L}^{-1}$, o 
limite máximo de índice de fenol é de $2,5 \mathrm{~g} \mathrm{~L}^{-1}$ e nenhuma menção é feita em relação ao índice de azul de metileno - IAM. Dessa forma, os CAPs 12, 13 e 14 não se enquadram nos padrões de fornecimento de carvão ativado pulverizado para aplicação no tratamento de água para abastecimento público.

O número de iodo está relacionado à microporosidade do carvão ativado, uma vez que requer poros com abertura inferior a $1 \mathrm{~nm}$ para ser adsorvida (EL-HENDAWY et al., 2001), ao passo que o índice de azul de metileno está relacionado à mesoporosidade do carvão ativado pois requer poros com abertura próxima a $2 \mathrm{~nm}$ (WARHURST et al., 1997).

Assim, para lixiviados estabilizados com presença de moléculas orgânicas de elevada massa molecular, como as substâncias húmicas, os carvões de porosidade desenvolvida com predominância de mesoporos podem ser mais eficientes do que os microporosos. Diante dessa hipótese, os resultados da caracterização preliminar em função Índice de Azul de Metileno indicam que os CAPs mais apropriados para essa aplicação são os CAPs: importados CAP7 e CAP8 e nacionais CAP5, CAP9 e CAP14.

\section{Experimento de adsorção aliada à coagulação química, floculação e sedimentação}

Os resultados de cor verdadeira e turbidez residuais do experimento para seleção dos CAPs de melhor desempenho são apresentados no Gráfico 1. 
Gráfico 1 - Resultados de cor verdadeira e turbidez residuais do experimento para os CAPs (1 a 14) amostrados



Os melhores resultados foram obtidos para o CAP7 e CAP8. Entretanto, como ambos são importados do mesmo fabricante, mesma matéria prima e método de ativação, optou-se pela seleção de apenas um tipo de carvão importado, o CAP7. Dentre os CAPs nacionais, foram selecionados o CAP5 e o CAP9 considerando os resultados em relação à cor verdadeira residual.

Dos resultados obtidos para cor verdadeira correlacionados aos índices de adsorção da caracterização dos CAPs, pôde-se verificar que não houve relação direta entre a eficiência observada e o NI ou IF para os carvões empregados. Em contrapartida, observa-se no Gráfico 2 estreita relação entre os valores de cor verdadeira residual e IAM dos CAPs amostrados, com $R^{2}$ de 0,93 , sendo os CAPs mais eficientes aqueles de maior IAM, reafirmando a hipótese de que os mesoporos constituem os sítios de adsorção de moléculas orgânicas de elevada massa molecular que conferem cor ao lixiviado como as substâncias húmicas. 
Gráfico 2- Correlação dos resultados de IAM e cor verdadeira residual do experimento para os CAPs (1 a 14) amostrados.

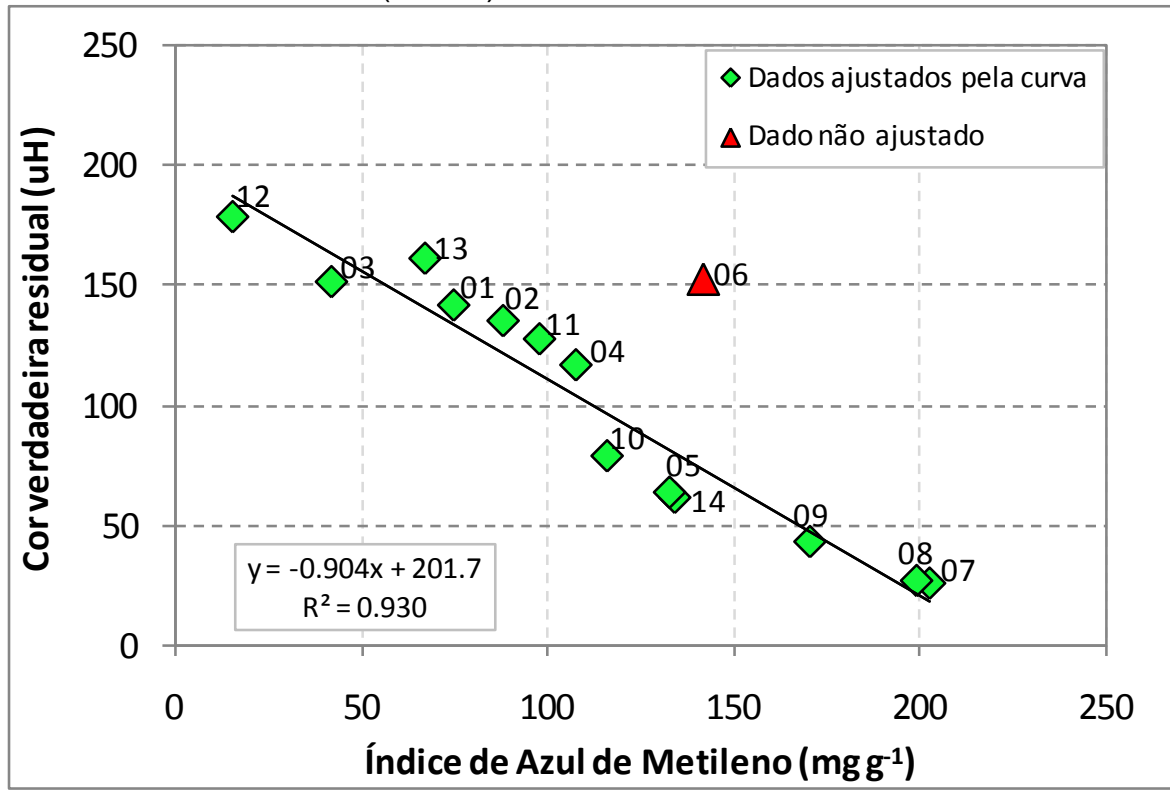

O CAP6 apresentou comportamento atípico em relação aos demais carvões amostrados. Entretanto vale ressaltar que esse CAP refere-se ao carvão importado de origem mineral betuminosa, cuja aplicação é pouco explorada na literatura referente ao tratamento de efluentes.

\section{CONCLUSÕES}

Dentre os carvões ativados pulverizados amostrados os que apresentaram maior eficiência foram:

7 e 8 - importados, provenientes do osso;

5 e 9 - nacionais, provenientes da madeira.

Os índices de adsorção de Número de lodo e Fenol não apresentaram relação direta na eficiência observada para caracterização dos carvões ativados pulverizados. Em contrapartida o Índica de Azul de Metileno mostrou ser um parâmetro adequado para a caracterização dos carvões ativados pulverizados em relação a capacidade de adsorção de matéria orgânica correlacionada a cor verdadeira em lixiviados estabilizados de aterro. 


\section{REFERÊNCIAS BIBLIOGRÁFICAS}

ALVIM, C. A. do N. Influências do pré-tratamento por stripping na desnitrificação convencional e pela via curta em RBS, aplicado ao tratamento de lixiviado de aterro sanitário. 2008. Dissertação apresentada ao Programa de Pós-Graduação em Engenharia de Edificações e Saneamento, Universidade Estadual de Londrina, Londrina, 2008.

AMOKRANE, A.; COMEL, C.; VERON, J. Landfill leachate pre-treatment by coagulationflocculation. Water Resources, v. 31, n. 11, p. 2775-2782, 1997.

APHA; AWWA; WEF. Standard Methods for the Examination of Water and

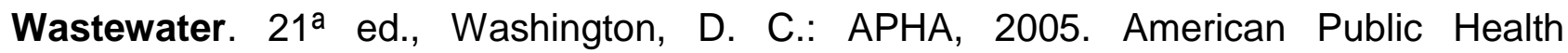
Association (APHA), American Water Works Association (AWWA), Water Environment Federation (WEF).

ASSOCIAÇÃO BRASILEIRA DE NORMAS TÉCNICAS - ABNT, Carvão ativado pulverizado para tratamento de água - especificação.NBR 11834:1991/EB - 2133. Rio de Janeiro, 1991.

ASSOCIAÇÃO BRASILEIRA DE NORMAS TÉCNICAS - ABNT, Carvão ativado pulverizado - Determinação do número de iodo - método de ensaio. NBR 12073:1991. Rio de Janeiro, 1991.

ASSOCIAÇÃO BRASILEIRA DE NORMAS TÉCNICAS - ABNT, Carvão ativado pulverizado - Determinação do índice de fenol - método de ensaio. NBR 12074:1991/MB 3411. Rio de Janeiro, 1991.

ASSOCIAÇÃO BRASILEIRA DE NORMAS TÉCNICAS - ABNT, Amostragem de carvão ativado pulverizado - procedimento.NBR 12280:1991. Rio de Janeiro, 1991. 
BAÇAOUI, A.; YAACOUBI, A.; DAHBI, A.; BENNOUNA, C.; PHAN TAN LUU, R.; MALDONADO-HODAR, F. J.; RIVERA-UTRILLA, J.; MORENO-CASTILLA, C. Activated carbon production from Morrocan olive-waste cakes. Carbon, v. 39, p. 425-432, 2001.

BANSAL, R. C.; DONNET, J. B.; STOECKLI, F. Active Carbon. New York: Marcel Dekker, inc., 1988.

BRASIL, Ministério do Meio Ambiente. Conselho Nacional de Meio Ambiente. Resolução no 357, 17 de março de 2005. Dispõe sobre a classificação dos corpos 146 de água e diretrizes ambientais para o seu enquadramento, bem como estabelece as condições e padrões de lançamento de efluentes, e dá outras providências. Brasília, 2005.

BRASIL, Ministério do Meio Ambiente. Conselho Nacional de Meio Ambiente. Resolução no 430, 13 de maio de 2011. Dispõe sobre as condições e padrões de lançamento de efluentes, complementa e altera a resolução n ${ }^{\circ} 357$ de 17 de março de 2005, do Conselho Nacional do Meio Ambiente - CONAMA. Brasília, 2011.

CASTRO, A. P. Influência da adição de polieletrólito no processo de floculação como pós-tratamento de lixiviado de aterro sanitário visando á remoção de carga orgânica recalcitrante. 2012. Dissertação apresentada ao Programa de Pós-Graduação em Engenharia de Edificações e Saneamento, Universidade Estadual de Londrina, Londrina, 2012.

CEFIC - Conseil Européen des Fédérations de l'industrie Chimique. Test methods for activated carbon, 1986.

EL-HENDAWY, A. N. A.; SAMRA, S. E.; GIRGIS, B. S. Adsorption characteristics of activated carbons obtained from corncobs. Colloids and surfaces A: physicochemical and engineergins aspects, v. 180, p. 209-221, 2001.

FELICI, E.M. Coagulação-floculação-sedimentação como pós-tratamento de efluente de sistema biológico em batelada aplicado a lixiviado de aterro de resíduos sólidos urbanos.2010. Dissertação apresentada ao Programa de Pós-Graduação em Engenharia de Edificações e Saneamento, Universidade Estadual de Londrina, Londrina, 2010. 
HOSSAKA, A. L. Tratamento biológico de lixiviados de aterro sanitário, utilizando como pré-tratamento a remoção parcial de $\mathrm{N}$-amoniacal por stripping. 2008. Dissertação apresentada ao Programa de Pós-Graduação em Engenharia de Edificações e Saneamento, Universidade Estadual de Londrina, Londrina, 2008.

IUPAC Recommendations. Pure and Applied Chemistry.v. 57, n. 4, p. 603-619, 1985.

JANKOWSKA, H.; SWIATKOWSKI, A.; CHOMA, J. Active Carbon. Chichester.: Horwood Publishing Limited, 1991.

JAPANESE INDUSTRIAL STANDARD - JIS K 1474. Test Methods for activated carbon. Japanese Standards Association, Tokyo, 1991.

KAWAHIGASHI, F. Aplicabilidade do pós-tratamento de lixiviados de aterro sanitário por adsorção em carvão ativado granular e avaliação ecotoxicológica. 2012. Dissertação apresentada ao Programa de Pós-Graduação em Engenharia de Edificações e Saneamento, Universidade Estadual de Londrina, Londrina, 2012.

KURNIAWAN, T. A.; LO, W.; CHAN, G. Y. Physico-chemical treatments for removal of recalcitrant contaminants from landfill leachate. Journal of Hazardous Materials, v. 129, n. 1, p. 80-100, Fev. 2006.

KURODA, E. K.; ALBUQUERQUE JR, E. C.; DI BERNARDO, L.; TROFINO, J. C. Caracterização e escolha do tipo de carvão ativado a ser empregado no tratamento de águas contendo microcistinas. XXIII Congresso Brasileiro de Engenharia Sanitária e Ambiental, Campo Grande - MS, Set. 2005.

KURODA, E. K. Remoção de células e subprodutos de microcystis spp. por dupla filtração, oxidação e adsorção. 2006. Tese apresentada à Escola de Engenharia de São Carlos, Universidade de São Paulo. São Carlos, 2006.

MALER, C. L. Aplicação do processo Fenton a diferentes etapas do tratamento de lixiviados de aterro sanitário 2013. Dissertação apresentada ao Programa de Pós- 
Graduação em Engenharia de Edificações e Saneamento, Universidade Estadual de Londrina, Londrina, 2013.

MODIN, H.; PERSSON, K. M.; ANDERSSON, A.; VAN., P. M. Removal of metals from landfill leachate by sorption to activated carbon, bone meal and iron fines. Journal of Hazardous Materials, v. 189, n. 3, p. 749-754, Mai. 2011.

PACHECO, J. R.; PERALTA-ZAMORA, P.G. Integração de processos físico-químicos e oxidativos avançados para remediação de percolado de aterro sanitário (chorume). Rev Bras Eng Sanit Amb, v.9, n.4, p. 306-311, 2004.

PARANÁ, Conselho Nacional do Meio Ambiente. Resolução 0070/2009 - CEMA. Dispõe sobre o licenciamento ambiental, estabelece condições e critérios e dá outras providências, para Empreendimentos Industriais. Curitiba, 2009.

PARANÁ, Conselho Nacional do Meio Ambiente. Resolução 081/2010 - CEMA. Dispõe sobre critérios e padrões de ecotoxicidade para o controle de efluentes líquidos lançados em águas superficiais no estado do Paraná. Curitiba, 2010.

POZZETTI, J. D. C.; MENDES, M. B.; FUJII, E. H.; KOSHIGOE, A. S. H.; KURODA, E. K. Coagulação química de lixiviado estabilizado de aterro sanitário. XXVII Congresso Brasileiro de Engenharia Sanitária e Ambiental, Goiânia - GO, Set. 2013.

QUEIROZ, L. M.; AMARAL, M. S.; MORITA, D. M.; YABROUDI, S. C.; SOBRINHO, P. A. Engenharia Sanitária e Ambiental, v. 16, n. 4, p. 403-410, Out./Dez 2011.

SANTOS, I. M. de B. T. Diagnóstico e avaliação da gestão de lixiviados produzidos em aterros sanitários de resíduos urbanos. 2008. Dissertação apresentada ao programa de pós-graduação em Engenharia do Ambiente, Faculdade de Ciências e Tecnologia da Universidade Nova de Lisboa, Lisboa, 2008. 
SCHALCH, V., LOPES, A. A. Gestão integrada dos resíduos sólidos urbanos e minimização dos impactos ambientais, ICTR - Instituto de Ciência e Tecnologia em Resíduos e Desenvolvimento Sustentável, Congresso Brasileiro de Ciência e Tecnologia em Resíduos e Desenvolvimento Sustentável, Costão do Santinho - Florianópolis - Santa Catarina 2004.

SLETTEN, R. S.; BENJAMIN, M. M.; HORNG, J. J.; FERGUSON, J. F. Physical-chemical treatment of landfill leachate for metals removal. Water Research, v. 29, n. 10, p. 23762386, Jan. 1995.

WARHURST, A. M.; MCCONNACHIE, G. L.; POLLARD, S. J. T. Characterization and applications of activated carbon produced from moringa oleifera seed husk by syngle-step steam pirolysis. Water Research, v. 31, p. 759-766, 1997.

WEI, L.; TAO, H.; QIXING, Z.; SHUGUANG, Z.; FENGXIANG, L. Treatment of stabilized landfill leachate by the combined process of coagulation/flocculation and powder activated carbon adsorption. Desalination, v. 264, n. 1, p. 56-62, Ago. 2010 